\title{
Towards streamlined bank vole odor preference evaluation using Y-mazes
}

\author{
Mattias Engman $^{1}$ (1) $\cdot$ Fredrik Schlyter $^{2,3} \cdot$ Paweł Koteja $^{4} \cdot$ Göran Birgersson $^{2} \cdot$ Gert Olsson $^{5} \cdot$ Johanna Witzell $^{1}$. \\ Magnus Löf ${ }^{1}$
}

Received: 20 December 2018 / Accepted: 4 July 2019 / Published online: 9 August 2019

(C) The Author(s) 2019

\begin{abstract}
Seed consumption by rodents causes substantial economic losses in agriculture and forest restoration. Rodents rely on their sensitive sense of smell to gather information about their environment. However, comparably little is known about how rodents use olfaction to locate food. We used bank voles to measure attraction to acorn odors in a Y-maze. Preferences were measured using two behaviors: approaching (time spent in odor preference zones) and investigation (numbers of nose pokes in odor nozzle), which yielded similar results. Shorter time intervals (15 and $30 \mathrm{~s}$ ) in the preference zones were at least as good as the longer time interval $(60 \mathrm{~s})$ for detecting differences in approaching behavior. In this way, it is possible to reduce the measurement time with approximately $50 \%$. Investigation, which was evaluated using only one time interval ( $180 \mathrm{~s}$ ), yielded longer measurement time. Acorns were as preferred as the familiar, standard food (rodent chow) while an acorn aeration extract did not produce any response. We conclude that short measurement times for the evaluation of attractive odors makes it possible to efficiently assay the wide range of volatile compounds from bank voles' natural foods which may be important in studies wishing to develop new rodent control methods.
\end{abstract}

Keywords Arvicolinae $\cdot$ Food preferences $\cdot$ Method $\cdot$ M. glareolus $\cdot$ Smell $\cdot$ Quercus

\section{Introduction}

Many plants rely on rodents for seed dispersal, but rodents are also effective consumers of seeds and may therefore

Communicated by: Magdalena Niedziałkowska

Mattias Engman

mattias.engman@slu.se

1 Southern Swedish Forest Research Centre, Swedish University of Agricultural Sciences, P.O. Box 49, 23053 Alnarp, Sweden

2 Department of Plant Protection Biology, Swedish University of Agricultural Sciences, P.O. Box 102, 23053 Alnarp, Sweden

3 Present address: Excellent Team for Mitigation, Faculty of Forestry \& Wood Sciences, Czech University of Life Sciences Prague, Kamycka 129, Prague 6, 16521 Suchdol, Czech Republic

4 Institute of Environmental Sciences, Jagiellonian University, ul. Gronostajowa 7, 30-387 Kraków, Poland

5 Department of Wildlife, Fish, and Environmental Studies, Swedish University of Agricultural Sciences, Umeå, Sweden substantially reduce the amounts of seeds (Vander Wall 2001; Hirsch et al. 2012). In rice (Oryza spp) seed production, foraging rodents may cause great losses and for instance in Asia, the estimated pre-harvest loss per year caused by rodents could feed 180 million people (Singleton 2003). Moreover, in forests, granivorous rodents can consume and disperse large quantities of seeds such as acorns (Quercus spp) and other nuts, thereby influencing regeneration dynamics (Crawley and Long 1995; den Ouden et al. 2005) and hinder direct seeding operations used in forest restoration (Birkedal et al. 2009, 2010; Leverkus et al. 2015).

Rodents rely heavily on olfaction to sense their environment, using a subset of the nearly endless varieties of volatile organic compounds. They use odors to communicate (Arakawa et al. 2008), identify the health or reproductive status of conspecifics (Beauchamp and Yamazaki 2003; Ferkin et al. 2004), and determine presence of predators (Apfelbach et al. 2005; Bytheway et al. 2013). In addition, rodents use olfaction as their primary and most important sense to find food, especially when foraging in the dark or when prey is hidden in soil or plant matter (Vander Wall et al. 2003; Taraborelli et al. 2009). 
To locate food, rodents use the spatial variation in odor concentration (Carthey et al. 2011; Gire et al. 2016). Odor concentration varies with the distance to the odor source (Gire et al. 2016) and the quantity of odors the source emits (Geluso 2005). Therefore, many seeds emit low amounts of odors to avoid predation (Hollander et al. 2012; Paulsen et al. 2013), a strategy known as chemical crypsis (Ruxton 2009). In applied ecology, a possible way to artificially reduce the spatial variation of odor concentration and therefore predation on seeds would be to camouflage it by large-scale application of natural or artificial food volatiles. Such camouflage has the potential to reduce foraging efficiency (Carthey et al. 2011; Gire et al. 2016) or cause prey switching (Price and Banks 2016). Despite the ecological and economic importance of seed consumption by granivorous rodents, we still know little about the volatile organic compounds rodents use to locate food. This lack of knowledge hinders development of cost-effective interventions.

To quantitatively study animal odor preference, different bioassays are used. Two-choice assays, such as the Y-maze, are commonly used to measure rodents' attraction (Ferkin and Rutka 1990; Bakker et al. 2002; Radwan et al. 2008; Bímová et al. 2011), aversion (Kavaliers and Colwell 1995; Kavaliers et al. 2001), and discrimination of odors (Singer et al. 1997). Most commonly, the time or frequency of animals approaching an odor, or odorized compartment, is measured. This measure has the benefit of not requiring any training of the animal. It has, however, been criticized because the test subject may not have to enter the odorized compartment to sense the odor and also one compartment may randomly be preferred simply because it is the first one the animal enters or make a territory marking in (Slotnick and Schellinck 2002; Doty 2003). To avoid such bias, other measures have been developed. One example is to measure an individual's investigative effort by using the duration of visit or number of nose pokes into an odorized source (Doty 2003; Mandairon et al. 2009; Qiu et al. 2014; Wernecke and Fendt 2015). The odor source consists of one or more holes, located either in the chamber floor or walls. On the other side of the hole, a detector records nose pokes from the animal investigating the odor. Nose pokes into holes have traditionally been used to study exploratory behavior in laboratory rodents, where an increase in nose pokes has been assumed to reflect an increase in propensity to explore (Takeda et al. 1998). Many studies using nose pokes to assess odor attraction have used laboratory rodents with limited genetic variability. Such animals may be more cautious (Coulston et al. 1993) and show less variation in exploratory behavior between individuals (De Boer et al. 2003). Therefore it is possible that genetic variable rodent strains may respond differently in a nose poke behavioral assay depending on individual variation in behaviors such as exploration rather than olfactory preference.

Bank voles (Myodes glareolus Schreber) are one of the most common seed predators in Europe (Mitchell-Jones et al. 1999). It is a generalist species feeding on diet ranging from lichens and herbs to seeds and insects (Drozdz 1966; Hansson 1971). During autumn when seed fall occurs in many oaks (Quercus spp.), bank voles consume and scatter hoard high amounts of these seeds (Jensen and Nielsen 1986. As a consequence of their effective foraging, bank voles may both act as an important seed disperser but also has the potential to consume all seeds produced in 1 year (Jensen 1982; Jensen and Nielsen 1986).

The aim of this study was to provide guidelines for quantitative studies of food odor attractive to bank voles. To achieve this goal, we (1) compared the effectiveness of two exploratory behaviors, spatially approaching an odor and investigating an odor with the nose; (2) evaluated different measurement time intervals; (3) analyzed odor compounds from acorns (Quercus robur L.) and evaluated bank voles' preference to odor extracts. We measured both behaviors in a Ymaze set-up to assess odor preference for acorns. To find the active volatile cues, a large number of compounds must be tested in bioassays, so the efficiency of different kinds of bioassays is of great interest to researchers.

\section{Material and methods}

\section{Design of bioassay}

The behavioral study was conducted on bank voles from an experimental colony maintained at the Jagiellonian University (Kraków, Poland), in May-June 2016. We evaluated the behaviors in five two-choice treatment combinations using Ymazes (Fig. 1). The Y-mazes were placed in a behavior room located inside the animal facility. The following five twochoice treatment combinations were selected to assess the suitability of the Y-maze to classify different aspects of odor preference: To evaluate bank voles' attraction to a novel but ecologically important food, (1) acorns were compared to active charcoal-filtered air (acorn-blank). To assess if the odorants from acorns could be extracted and still be as attractive to bank voles as acorns, (2) acorns were compared to acorn aeration extracts solved in pentane (acorn-extract). To investigate if acorns would be as preferred as the bank voles' familiar food, (3) acorns were compared to standard lab rodent chow (Labofeed H, Morawski, Kcynia, Poland) (acorn-rodent chow). To assess if an odor extract would be attractive at all, (4) acorn aeration extracts dissolved in pentane were compared to pentane (extract-solvent). To control for the solvent used, (5) pentane was compared to active charcoal-filtered air (solvent-blank).

The walls of the three Y-maze arms were constructed of aluminum and attached at $120^{\circ}$ angles (Fig. 1). Each arm of the maze was $37.5 \mathrm{~cm}$ long, $15 \mathrm{~cm}$ high, and $11 \mathrm{~cm}$ wide. The bottom was made of white polyamide plastic and the roof 
Fig. 1 Design of the Y-maze used in the two-choice behavioral trials including sizes of odor preference zones, placement of odor nozzles and the comfort zone

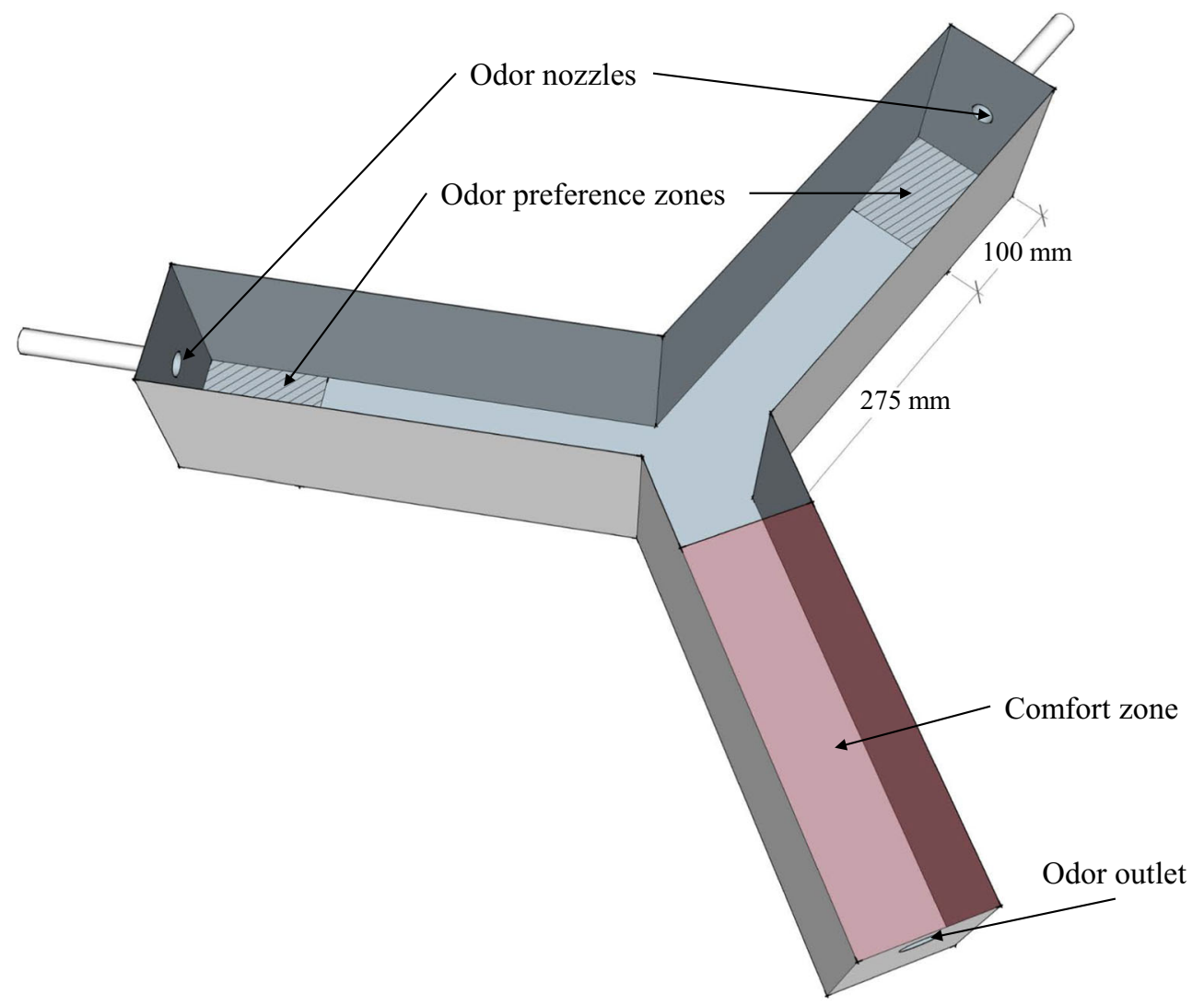

consisted of transparent acrylic glass. Odors were delivered in flexible polytetrafluoroethylene (PTFE) tubing from an adjacent observer room to an odor nozzle made of a polyamide cylinder $5 \mathrm{~cm}$ long and $2 \mathrm{~cm}$ wide with an 8 -mm hole drilled in the center. The nozzles were placed in the center of the distal end walls in the two odor treatment arms. The other ends of the flexible PTFE tubing odor sources were placed in $250 \mathrm{ml}$ gas wash bottles to which air was pumped by diaphragm vacuum pumps via an active charcoal filter. To deliver acorn odor, $100 \mathrm{~g}$ of acorns was put in the gas washing bottle. To ensure a steady release rate of dissolved odor compounds, custom-made "wick baits" (Lejfalk and Birgersson 1997) were put inside the gas washing bottles. These consisted of a 2-ml vial fitted with a screw cap in which a hole had been drilled. A PTFE tube (length $40 \mathrm{~mm} ; \varnothing 3 \mathrm{~mm}$ ), filled with cotton yarn wick, was inserted through the hole. To provide an initial preference of the third arm (comfort zone), red transparent acrylic glass was placed on top to dim the light, and a small amount of wood chips from the home cage were spread out on the floor in that zone.

We used six Y-mazes simultaneously in the behavior room. Three Y-mazes were placed on each side of the room, ca. $50 \mathrm{~cm}$ between Y-mazes and ca $100 \mathrm{~cm}$ between the two rows of Y-mazes. Before the tests, the voles were deprived of food for $1 \mathrm{~h}$ in their individual cages. They were then transferred singly to the comfort zone in the Y-mazes where they were habituated for another $2 \mathrm{~h}$ with clean air pumped into the choice arms with no access to food or water. For each treatment combination, treatments were randomly assigned to each arm of each Y-maze. When the trial started, odorized air according to the treatment assigned was pumped (at $250 \mathrm{~mL} \mathrm{~min}^{-1}$ ) into the two-choice arms. Each session with six Y-mazes lasted $1 \mathrm{~h}$ and each treatment combination was replicated 23 to 26 times, every time with new animals. Between sessions, the Y-mazes were carefully washed with warm water and soap. Thereafter, they were cleaned with ethanol $(70 \%)$, washed again with warm water, and then dried before next session.

\section{Animal and seed materials}

The bank vole colony was established from approximately 320 wild animals caught outside Krakow in 2000 and 2001 and was a basis for an artificial selection experiment (Sadowska et al. 2008). The behavioral assays in Y-mazes were performed on individuals from generation 21 of the selection experiment, but only on individuals sampled from non-selected control lines in which the animals were randomly bred (Sadowska et al. 2008). The animals were housed in standard plastic mouse cages with sawdust bedding, at a constant temperature $\left(20 \pm 1{ }^{\circ} \mathrm{C}\right)$ and photoperiod (16 h light, $8 \mathrm{~h}$ dark; light phase starting at 2:00 am). The odor-preference tests were conducted between 10:00 and 21:00. Water and food (a standard rodent chow 24\% 
protein, $3 \%$ fat, $4 \%$ fiber; Labofeed H, Kcynia, Poland) were provided ad libitum. At the time of testing, the animals were 61-85 days old. In total, we assayed 69 females and 56 males. Individual weight of the voles ranged from 14.2 to $33.2 \mathrm{~g}$ with a mean of $21.4 \mathrm{~g}$. Males were heavier than females (average weight $23.4 \mathrm{~g}$ and $19.8 \mathrm{~g}$, respectively) (Student $t$ test, $t=5.8292, p<0.001$ ).

Acorns of pedunculate oak (Quercus robur L.) were provided by a seed company in Denmark (Levinsen \& Abies A/S). Seeds from different years and sources had to be used and therefore may have varied in vitality. Seeds used in aeration (extract) had been collected in Puszcza Barlinecka, Poland during 2014, and seeds used in the behavioral trial were collected from a seed nursery in Knuthenborg, southern Denmark, in 2015. To decrease variation in moisture content which may affect seed volatile profile and seed weight, all acorns were soaked in water for $24 \mathrm{~h}$ prior to use (Bonner and Vozzo 1987; Colville et al. 2012). Acorns that floated were removed as they tend to be non-viable (Bonner and Vozzo 1987).

Volatiles from acorns were collected using aeration (dynamic headspace) with PTFE columns (length $40 \mathrm{~mm}$; ID $3 \mathrm{~mm}$ ) filled with Porapak Q (Waters Corp., Milford, MA, USA; $50 \mathrm{mg}$; mesh 50-80) as adsorbent. Acorns that had been soaked in water for $24 \mathrm{~h}$ were put in Toppits roasting bags (Cofresco Frischhalteprodukte GmbH \& Co., Minden, Germany) with $300 \mathrm{~g}( \pm 10)$ acorns in each bag $(n=7)$. The PFFE column was placed inside the cooking bag and connected via PTFE tubing to a diaphragm vacuum pump (KNF Neuberger, Freiburg, Germany), which created a continued flow (100土 $1 \mathrm{~mL} \mathrm{~min}^{-1}$ ). The inlet air was filtered through an active charcoal filter. Headspace volatiles were sampled for $4 \mathrm{~h}$ and then eluted with $500 \mu \mathrm{L}$ pentane. Four replicates of the dry lab rodent chow were sampled using the same method described above.

The eluted acorn aeration extracts were analyzed by combined gas chromatography and mass spectrometry (GC-MS) using an Agilent 7890A GC and a 5977 MS (Agilent Technologies Inc., Santa Clara, CA, USA). The GC-MS was equipped with a DB-Wax coated fused silica capillary column $(60 \mathrm{~m} \times 0.25 \mathrm{~mm} \times \mathrm{df}=0,25 \mu \mathrm{m}, \mathrm{J} \& \mathrm{~W}$, Agilent) and used helium at a constant flow of $35 \mathrm{~cm}^{3} \mathrm{~s}^{-1}$ as a mobile phase. Each sample was injected using a G4567A autoinjector (Agilent), with the injection volume set to $2 \mu \mathrm{L}$ in splitless $(30 \mathrm{~s})$ mode at $225^{\circ} \mathrm{C}$. The initial temperature of $30^{\circ} \mathrm{C}$ was held for $3 \mathrm{~min}$ and then increased by $8{ }^{\circ} \mathrm{C} \mathrm{min}{ }^{-1}$ until it had reached $225{ }^{\circ} \mathrm{C}$ which was maintained for $10 \mathrm{~min}$. MSD Chemstation (E.02.02.1431, Agilent Technologies) was used to identify peaks in the chromatograms. Mass spectra were compared to a local reference library and NIST14. The samples were quantified by an external reference mix of Kovats index $\left(\mathrm{C}_{8}-\mathrm{C}_{20}\right)$ $4 \mathrm{ng} \mu \mathrm{L}^{-1}$ analyzed using the same method as described above. The Kovats indices for each identified compound were calculated for confirmation of identifications.

\section{Measurements}

Odor preference was scored by two different behaviors: approaching and investigation. Approaching was measured as the cumulative time spent in each odor-preference zone, which was defined as the area $10 \mathrm{~cm}$ from the distal end of each choice arm in the Y-maze (Fig. 1). We used Ethovision XT (v. 9.0.718) video analysis software (Noldus, Wageningen, the Netherlands) to extract cumulative time when the animals had spent up to 15 , 30 , and $60 \mathrm{~s}$ in the odor-preference zones. Thus, approaching was measured cumulatively using both preference zones, so for example with the 15-s interval, it would end after an animal had spent $9 \mathrm{~s}$ in one odor preference zone and $6 \mathrm{~s}$ in the other. To assess if the different intervals would have any impact on the measurement time, we also extracted the time to finish an interval. The upper limit to which an animal had to reach the cumulatively measured intervals was set to $1 \mathrm{~h}$, i.e., equal to the time of the session.

Investigation was measured by the number of nose pokes (when the animal inserted its nose in the odor nozzle, Fig. 1) during a period of $3 \mathrm{~min}$ after the first nose poke had been performed by the animal. We decided to use a longer time interval for nose pokes as some individuals waited before they would perform additional nose pokes. The number of nose pokes was recorded manually by watching the video recordings.

\section{Data analysis}

As data were not normally distributed, we used Wilcoxon signed rank tests to assess olfactory preference in the twochoice assay for time spent in preference zones and nose pokes. To compare the effect size of both approaching and investigation, we calculated the standardized effect size Hedges' $g$, which divides the difference of means by their pooled standard deviation (Nakagawa and Cuthill 2007). To compare the measurement time for the three approach time intervals and investigation, we used Kruskal-Wallis rank sum test and subsequent pairwise comparisons were done using pairwise Wilcoxon rank sum test. R (v. 3.3.3) was used for all analyses (R Core Team 2017). We used the "effsize" (v 0.7.1) package to calculate effect sizes (Torchiano 2017). Commonly, a small, medium, and large effect size is considered to be $0.20,0.50$, and 0.80 , respectively (Cohen 1988). The "coin" (v 1.1-3) package (Hothorn et al. 2008) was used to calculate Wilcoxon signed ranks. Coin uses the Pratt method for handling ties (Hothorn et al. 2008). One vole which never left the comfort zone in the Y-maze was excluded from the analysis.

\section{Results}

Approaching (time spent in odor preference zones) and investigation (numbers of nose pokes in odor nozzle) yielded 
similar results. Acorns were overall more approached and investigated compared to blank and the odor extract for all three time intervals, as reflected in the effect sizes around 0.5 (Fig. 2). The other treatment combinations consistently produced non-significant results in both approaching and investigation.

Shorter time intervals (15 and $30 \mathrm{~s}$ ) were at least as good as the longer time interval $(60 \mathrm{~s})$ for detecting differences in approaching behavior between treatment combinations (Fig. 3) while investigation behavior was more ambiguous (Fig. 4). For example, bank voles significantly preferred the acorn odor over the blank air when measured for the two approaching intervals $15 \mathrm{~s}$ and $30 \mathrm{~s}$ and for investigation (15 s: $\mathrm{Z}=2.06, p=0.04 ; 30 \mathrm{~s}: \mathrm{Z}=2.19, p=0.03$; Investigation: $\mathrm{Z}=2.63, p<0.01)$. The same trend was found for the approaching interval $60 \mathrm{~s}$, but it was not statistically significant $(Z=1.76, p=0.08)$. In addition, for all three approaching time intervals, preference to acorn odor was also significantly higher when compared to the eluted aeration extract from acorns $(15 \mathrm{~s}: \mathrm{Z}=2.03, p=0.04 ; 30 \mathrm{~s}: \mathrm{Z}=2.30, p=$ $0.02 ; 60 \mathrm{~s}: Z=1.99, p=0.05$ ) but not when preference was quantified using investigation behavior $(Z=1.80, p=0.07)$. The slightly higher effect size in detecting differences between treatment combinations at short time intervals ( $15 \mathrm{~s}$ and $30 \mathrm{~s}$ ) is also visible in the falling numbers for all combination at the long time interval (60 s) (Fig. 2).

The measurement time was significantly different depending on approaching time intervals $(\mathrm{H}=78.46, p<0.01)$, and the two shorter intervals ( 15 and $30 \mathrm{~s}$ ) were significantly different from the longer interval $(60 \mathrm{~s})$ and also different from the investigation measurement $(p<0.01)$ (Fig. 5). The measurement time was on average 7.0, 8.4, 13.2, and $16.5 \mathrm{~min}$ for the $15 \mathrm{~s}, 30 \mathrm{~s}, 60 \mathrm{~s}$ approaching time intervals and the investigation measurement, respectively.

In the acorn aeration extract, terpenes were the most common compound groups with $\alpha$-pinene and limonene being the most abundant (Table 1). They were also the only two compounds which the acorn and rodent chow extract had in common, although the amounts were much higher in the acorn extract. In contrast, the most dominant compound groups in the rodent chow aeration extract were alcohols and aldehydes, with 1-hexanol and hexanal being the most abundant.

\section{Discussion}

The two behaviors (approaching and investigation) quantified showed a similar biological result, attraction to acorns, which indicates that both measures are useful when assessing odor preference of bank voles. The concern that study animals may sense odors in a Y-maze without entering a choice arm (Slotnick and Schellinck 2002; Doty 2003) was not a problem in our study, since the investigation behavior cannot be performed from a distance, and the results for approach and investigation were consistent. Some previous researches have failed in using Y-maze due to the bank voles refusing to move (Christiansen et al. 1977). However, in our study, the bank voles were bred in laboratory which has shown to increase their movement (Korpela et al. 2011). This, together with short time intervals, could explain the increased performance.

Shorter time intervals gave similar or larger effect compared to longer intervals, indicating that shorter intervals are more suitable than longer in bioassays of bank vole olfactory preference. This is in line with previous research on other rodent species showing that test animal's interest in the odor decreases quickly (Slotnick and Schellinck 2002). By using 15 -s intervals, it was also possible to reduce measurement time with almost $50 \%$ compared to $60 \mathrm{~s}$ and almost with $20 \%$ compared to $30 \mathrm{~s}$, thus allowing future research to streamline behavioral assays. Approaching required less measurement time than investigation. To reduce the measurement time for investigation, it would be possible to either reduce the
Fig. 2 Comparison of effect size among treatment combinations, where the higher effect size indicates a stronger effect (larger differences among treatments in a combination). Effect size calculated as Hedges' $g$. Treatment combinations: AC-B acorn-blank, AC-E acorn-extract, AC-RC acorn-rodent chow, S-B solvent-blank, and E-S extractsolvent

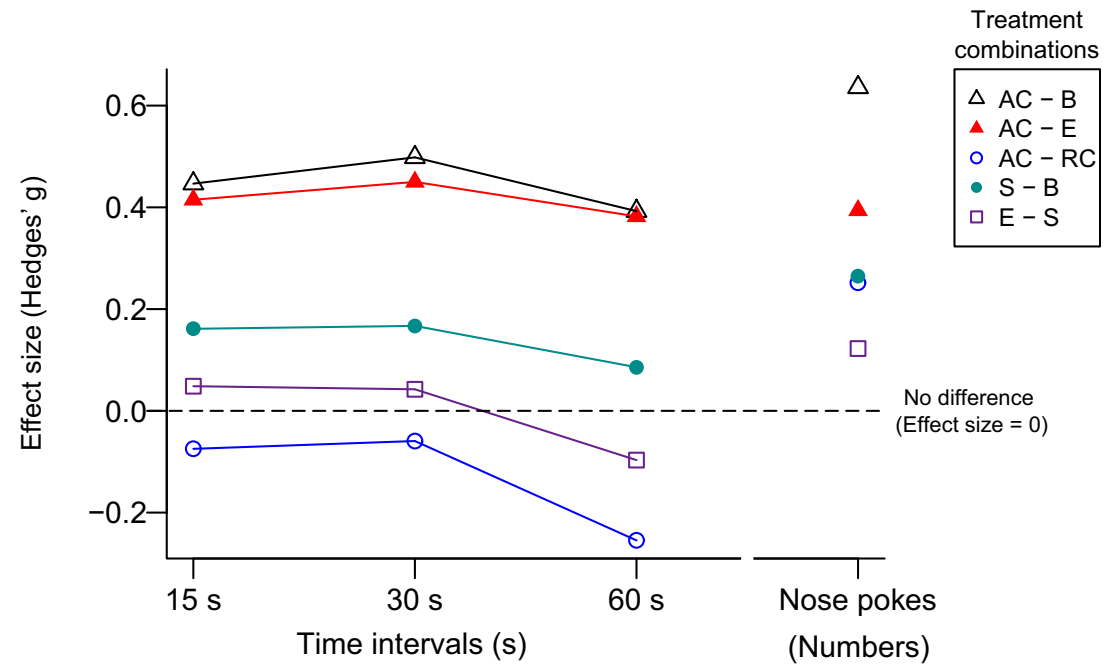


Fig. 3 The mean cumulative time bank voles spent in each choice arm for each of the five treatment combinations, and for three cumulative time intervals (seconds). Error bars indicate standard errors. Asterisks indicate statistical difference within treatment combination $(P \leq 0.05)$

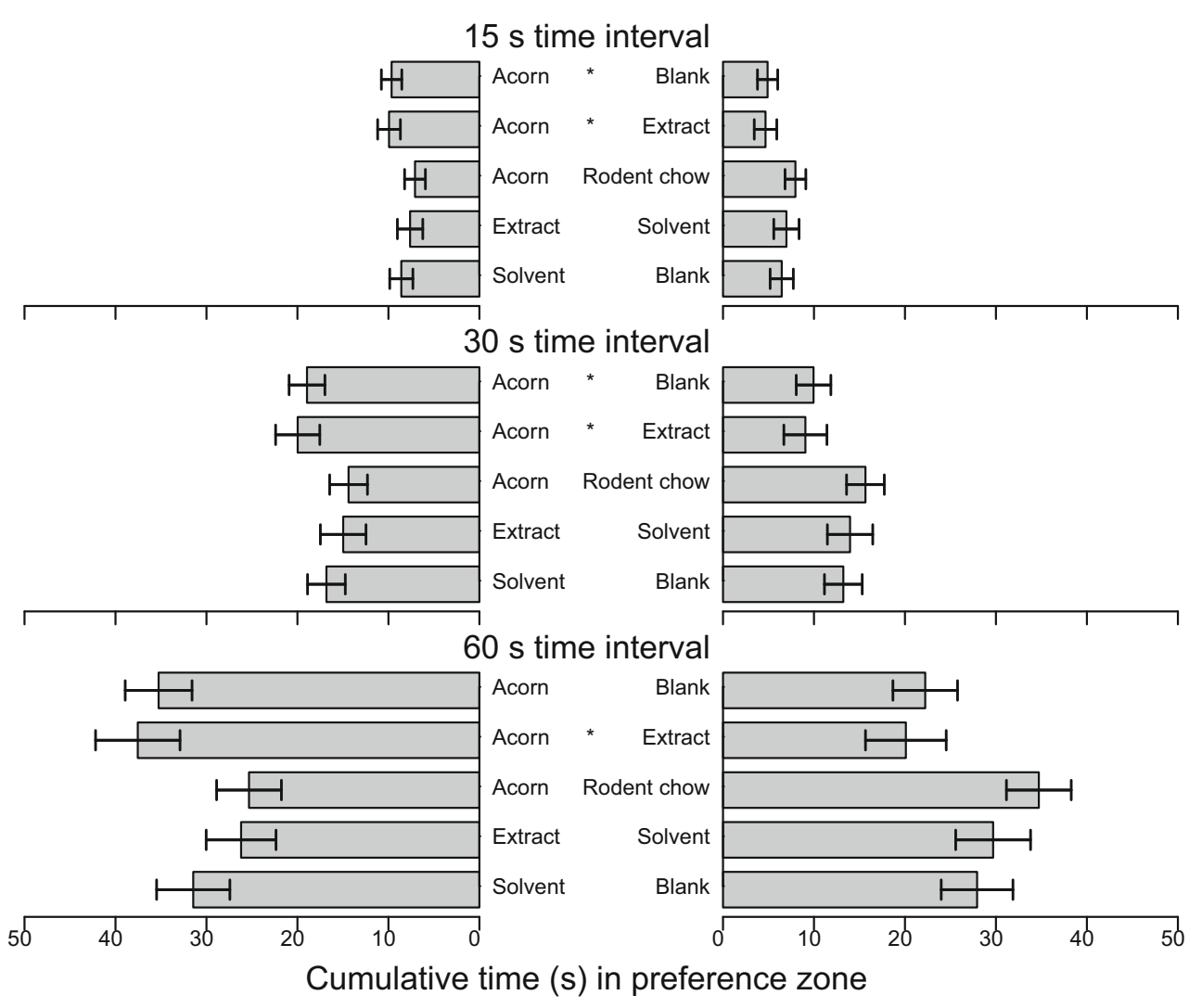

time interval from $180 \mathrm{~s}$ to for example $60 \mathrm{~s}$, or to reduce the time of the session. However, shorter time intervals or shorter sessions would result in less odor preference data since some individuals showed low activity in the beginning. The longer measurement time for investigation may also simply be a reflection of that some animals were aversive to novel situations and therefore showed less propensity to insert their noses into holes (Takeda et al. 1998).

In our study, there was no response from the animals to the eluted acorn aeration extract. The use of different solvents may sometimes explain why different extracts give rise to opposite effects, which for example can depend on the polarity of the attractive odor components (Eriksson et al. 2008). It could therefore be more suitable to use a more polar solvent such as an alcohol in this case. It may also be that the active compounds important for detection are only emitted in low amounts due to evolutionary pressure of escaping predation (Hollander et al. 2012) and therefore are difficult to trap using headspace methods. To our knowledge, seed odor extracts have seldom been used in olfactory assays of mammals. The most common compound group in our extract was monoterpenes. Terpenes can act both as attractants and repellents in a dose-dependent way (Bedoya-Pérez et al. 2014). It may be that the terpenes in the extract had a lower or higher release rate compared to the acorns and therefore were not identified as food or as food containing too high a concentration of deterrents. Further studies are required in this field.

Voles showed significant preference for acorn odors over blank odors, and acorns were as preferred as rodent chow. Preference for odors from a novel food (in this case acorns) may either be acquired through generalization of previously experienced food which share some common quality with the
Fig. 4 The mean number of nose pokes in the odor nozzles for each of the five treatment combinations, for a recording time of $3 \mathrm{~min}$. Error bars indicate standard errors. Asterisks indicate statistical difference within treatment combination $(P<0.01)$

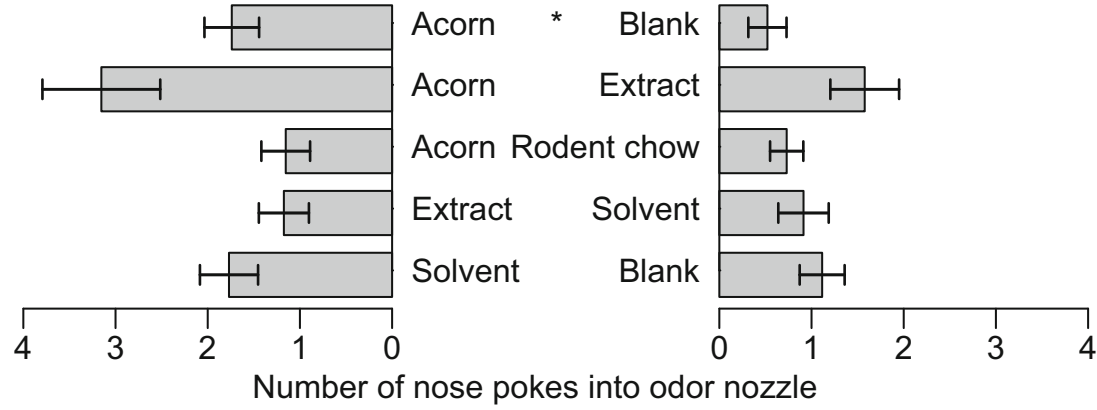




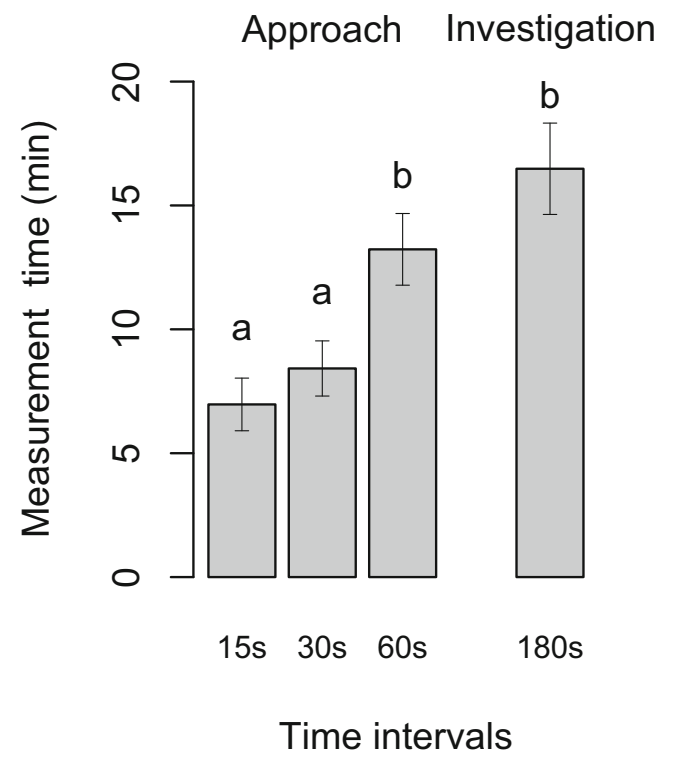

Fig. 5 Mean measurement time for the three approaching time intervals and for investigation. Error bars indicate standard errors. Different letters indicate significant differences $(p<0.01)$ novel food or result from an innate preference for it. To generalize foraging cues is beneficial for animals with a wide variety of food sources, such as bank voles (Hansson 1971), as odor and taste cues associated with one type of food can be used to find other foods with common perceptual qualities (Linster and Smith 1999; Villalba and Provenza 2000). Only two compounds, both plant secondary metabolites ( $\alpha$-Pinene $\&$ Limonene), overlapped in the aeration extracts of acorns and rodent chow, suggesting that rodent chow and acorns smell different and were not generalized. It may therefore be that in bank voles, acorn attraction is innate, as it is in other seed hoarding rodents, which express specific behaviors to acorns of even those oak species that have been locally extinct for centuries (Steele et al. 2006; Xiao and Zhang 2012).

To further reduce variation in studies similar to ours, care could be taken to match the voles diel rhythm as some of our voles were tested during their day-phase and others during the night. However, bank voles normally feed both during day and night (Hansson 1971).

This study demonstrates that data on food odor preference in bank voles can both be obtained using approach and
Table 1 Mean values of compounds from acorn and rodent chow headspace as analyzed using GC-MS (ng $\min ^{-1}$ )

\begin{tabular}{|c|c|c|c|}
\hline \multicolumn{2}{|l|}{ Compound } & \multirow{2}{*}{$\begin{array}{l}\text { Acorn } \\
11\end{array}$} & \multirow{2}{*}{$\begin{array}{l}\text { Rodent chow } \\
0.6\end{array}$} \\
\hline Monoterpene hydrocarbons & $\alpha$-Pinene & & \\
\hline & Camphene & 0.15 & \\
\hline & $\beta$-Pinene & 4.5 & \\
\hline & 3-Carene & 1.5 & \\
\hline & Myrcene & 1 & \\
\hline & Limonene & 9 & 2 \\
\hline & $\gamma$-Terpinene & 0.2 & \\
\hline & $\beta$-Phellandrene & 2.5 & \\
\hline & Sabinene & 0.15 & \\
\hline & Terpinolene & 0.15 & \\
\hline \multirow[t]{3}{*}{ Ketones } & 2-Methylcyclopentanone & 0.3 & \\
\hline & 2-Ethylcyclopentanone & 0.9 & \\
\hline & Acetoin & 0.2 & \\
\hline \multirow[t]{2}{*}{ Hydrocarbons } & Styrene & 0.45 & \\
\hline & $p$-Cymene & 0.9 & \\
\hline \multirow[t]{3}{*}{ Alcohols } & 1-Pentanol & & 1.5 \\
\hline & 1-Hexanol & & 4.5 \\
\hline & 1-Octen-3-ol & & 0.85 \\
\hline \multirow[t]{4}{*}{ Aldehydes } & Hexanal & & 11 \\
\hline & 2-Hexenal & & 0.5 \\
\hline & 2-Heptenal & & 0.3 \\
\hline & Octanal & & 0.3 \\
\hline \multirow[t]{3}{*}{ Others } & Benzaldehyde & & 1.2 \\
\hline & 5-Ethyl-2(5H)-furanone & & 0.8 \\
\hline & 5-Ethylcyclopent-1-ene c & & 0.3 \\
\hline
\end{tabular}

acetoin 3-hydroxy-2-butanaone 
investigation behaviors. Short measurement times for the evaluation of attractive odors make it possible to efficiently assay the wide range of compounds that are present in the volatile headspace of rodents' natural foods. Understanding how rodents use odors to locate food may in the future add important tools to control rodent populations and improve forest restoration and food security efforts.

Acknowledgments We are grateful to Uttaran Maiti for helping with setting the video tracking system and to several students for help with the animal maintenance. We thank JAPO Plast AB (SE) for supplying material free of charge.

Funding Open access funding provided by Swedish University of Agricultural Sciences. The work was funded by a donation from Professor Lars Tirén. The cost of the animals was covered from grants of the Polish National Science Centre and the Jagiellonian University to P.K. (2014/13/B/NZ8/04683 and DS/WBINOZ/INOS/757).

\section{Compliance with ethical standards}

The animal colony was maintained according to a permit from the Local Ethical Committee in Krakow, Poland (No. 170/2014; the non-invasive odor-preference tests did not require a specific additional permit).

Competing interests The authors declare that they have no competing interests.

Open Access This article is distributed under the terms of the Creative Commons Attribution 4.0 International License (http:// creativecommons.org/licenses/by/4.0/), which permits unrestricted use, distribution, and reproduction in any medium, provided you give appropriate credit to the original author(s) and the source, provide a link to the Creative Commons license, and indicate if changes were made.

\section{References}

Apfelbach R, Blanchard CD, Blanchard RJ, Hayes RA, McGregor IS (2005) The effects of predator odors in mammalian prey species: a review of field and laboratory studies. Neurosci Biobehav Rev 29: 1123-1144. https://doi.org/10.1016/j.neubiorev.2005.05.005

Arakawa H, Blanchard DC, Arakawa K, Dunlap C, Blanchard RJ (2008) Scent marking behavior as an odorant communication in mice. Neurosci Biobehav Rev 32:1236-1248. https://doi.org/10.1016/j. neubiorev.2008.05.012

Bakker J, Honda S, Harada N, Balthazart J (2002) The aromatase knockout mouse provides new evidence that estradiol is required during development in the female for the expression of sociosexual behaviors in adulthood. J Neurosci 22:9104-9112

Beauchamp GK, Yamazaki K (2003) Chemical signalling in mice. Biochem Soc Trans 31:147-151. https://doi.org/10.1042/BST0310147

Bedoya-Pérez MA, Isler I, Banks PB, McArthur C (2014) Roles of the volatile terpene, 1,8-cineole, in plant-herbivore interactions: a foraging odor cue as well as a toxin? Oecologia 174:827-837. https:// doi.org/10.1007/s00442-013-2801-x

Bímová BV, MacHolán M, Baird SJE et al (2011) Reinforcement selection acting on the European house mouse hybrid zone. Mol Ecol 20: 2403-2424. https://doi.org/10.1111/j.1365-294X.2011.05106.x
Birkedal M, Fischer A, Karlsson M, Löf M, Madsen P (2009) Rodent impact on establishment of direct-seeded Fagus sylvatica, Quercus robur and Quercus petraea on forest land. Scand J For Res 24:298307. https://doi.org/10.1080/02827580903055125

Birkedal M, Löf M, Olsson GE, Bergsten U (2010) Effects of granivorous rodents on direct seeding of oak and beech in relation to site preparation and sowing date. For Ecol Manag 259:2382-2389. https:// doi.org/10.1016/j.foreco.2010.03.014

Bonner FT, Vozzo JA (1987) Seed biology and technology of Quercus. General Technical Report SO-66. USDA, Forest Service, Southern Forest Experiment Station, New Orleans

Bytheway JP, Carthey AJR, Banks PB (2013) Risk vs. reward: how predators and prey respond to aging olfactory cues. Behav Ecol Sociobiol 67:715-725. https://doi.org/10.1007/s00265-013-1494-9

Carthey AJR, Bytheway JP, Banks PB (2011) Negotiating a noisy, information-rich environment in search of cryptic prey: olfactory predators need patchiness in prey cues. J Anim Ecol 80:742-752. https://doi.org/10.1111/j.1365-2656.2011.01817.x

Christiansen E, Døving KB, Mørk E (1977) A device for bioassay of response to olfactory stimuli in wild rodents. In: Test methods for vertebrate pest control and management materials. ASTM International, Baltimore, pp 27-30

Cohen J (1988) Statistical power analysis for the behavioral sciences, 2nd edn. Lawrence Erlbaum Associates, New Jersey

Colville L, Bradley EL, Loyd AS et al (2012) Volatile fingerprints of seeds of four species indicate the involvement of alcoholic fermentation, lipid peroxidation, and Maillard reactions in seed deterioration during ageing and desiccation stress. J Exp Bot 63:6519-6530. https://doi.org/10.1093/jxb/err313

Coulston S, Stoddart DM, Crump DR (1993) Use of predator odors to protect chick-peas from predation by laboratory and wild mice. $\mathrm{J}$ Chem Ecol 19:607-612. https://doi.org/10.1007/BF00984995

Crawley MJ, Long CR (1995) Alternate bearing, predator satiation and seedling recruitment in Quercus Robur L. J Ecol 83:683-696

De Boer SF, Van der Vegt BJ, Koolhaas JM (2003) Individual variation in aggression of feral rodent strains: a standard for the genetics of aggression and violence? Behav Genet 33:485-501. https://doi. org/10.1023/A:1025766415159

den Ouden J, Jansen PA, Smit R (2005) Jays, mice and oaks: predation and dispersal of Quercus robur and Q. petraea in North-Western Europe. In: Seed fate: predation, dispersal and seedling establishment. CABI, Wallingford, pp 223-239

Doty RL (2003) Methods for determining odor preferences in nonhuman mammals. In: Doty RL (ed) Handbook of Olfaction and Gustation, 2nd edn, pp 403-408

Drozdz (1966) Food habits and food supply of rodents in the Beech Forest. Acta Theriol (Warsz) 164:363-384. https://doi.org/10. 1099/mic. 0.000618

Eriksson C, Månsson PE, Sjödin K, Schlyter F (2008) Antifeedants and feeding stimulants in bark extracts of ten woody non-host species of the pine weevil, Hylobius abietis. J Chem Ecol 34:1290-1297. https://doi.org/10.1007/s10886-008-9525-0

Ferkin MH, Rutka TF (1990) Mechanisms of sibling recognition in meadow voles. Can J Zool 68:609-613

Ferkin MH, Lee DN, Leonard ST (2004) The reproductive state of female voles affects their scent marking behavior and the responses of male conspecifics to such marks. Ethology 110:257-272. https://doi.org/ 10.1111/j.1439-0310.2004.00961.x

Geluso K (2005) Benefits of small-sized caches for scatter-hoarding rodents: influence of cache size, depth, and soil moisture. J Mammal 86:1186-1192. https://doi.org/10.1644/05-MAMM-A-016R1.1

Gire DH, Kapoor V, Arrighi-allisan A et al (2016) Article mice develop efficient strategies for foraging and navigation using complex natural stimuli. Curr Biol 26:1261-1273. https://doi.org/10.1016/j.cub. 2016.03.040 
Hansson L (1971) Small rodent food, feeding and population dynamics. Oikos 22:183-198

Hirsch BT, Kays R, Pereira VE, Jansen PA (2012) Directed seed dispersal towards areas with low conspecific tree density by a scatter-hoarding rodent. Ecol Lett 15:1423-1429. https://doi.org/10.1111/ele.12000

Hollander JL, Vander WSB, Longland WS (2012) Olfactory detection of caches containing wildland versus cultivated seeds by granivorous rodents. West North Am Nat 72:339-347. https://doi.org/10.3398/ 064.072.0308

Hothorn T, Hornik K, van de Wiel M, Zeileis A (2008) Implementing a class of permutation tests: the coin package. J Stat Softw 28:1-23. https://doi.org/10.18637/jss.v028.i08

Jensen TS (1982) Seed production and outbreaks of non-cyclic rodent populations in deciduous forests. Oecologia 54:184-192. https://doi. org/10.1007/BF00378391

Jensen TS, Nielsen OF (1986) Rodents as seed dispersers in a heath - oak wood succession. Oecologia 70:214-221. https://doi.org/10.1007/ BF00379242

Kavaliers M, Colwell DD (1995) Odours of parasitized males induce aversive responses in female mice. Anim Behav 50:1161-1169. https://doi.org/10.1016/0003-3472(95)80032-8

Kavaliers M, Choleris E, Colwell DD (2001) Brief exposure to female odors "emboldens" male mice by reducing predator-induced behavioral and hormonal responses. Horm Behav 40:497-509. https://doi. org/10.1006/hbeh.2001.1714

Korpela K, Sundell J, Ylönen H (2011) Does personality in small rodents vary depending on population density? Oecologia 67-77. https:// doi.org/10.1007/s00442-010-1810-2

Lejfalk C, Birgersson G (1997) Wick-baits-a novel delivery system for testing potential semiochemicals. Abstract, 14th Annual Meeting of the International Society of Chemical Ecology Vancouver, July 12 $16, \mathrm{p} 31$

Leverkus AB, Rojo M, Castro J (2015) Habitat complexity and individual acorn protectors enhance the post-fire restoration of oak forests via seed sowing. Ecol Eng 83:276-280. https://doi.org/10.1016/j. ecoleng.2015.06.033

Linster C, Smith BH (1999) Generalization between binary odor mixtures and their components in the rat. Physiol Behav 66:701-707. https:// doi.org/10.1016/S0031-9384(99)00007-4

Mandairon N, Sultan S, Rey N, Kermen F, Moreno M, Busto G, Farget V, Messaoudi B, Thevenet M, Didier A (2009) A computer-assisted odorized hole-board for testing olfactory perception in mice. J Neurosci Methods 180:296-303. https://doi.org/10.1016/j. jneumeth.2009.04.008

Mitchell-Jones AJ, Bogdanowicz W, Krystufek B, et al (1999) The atlas of European mammals. T \& AD Poyser, London

Nakagawa S, Cuthill IC (2007) Effect size, confidence interval and statistical significance: a practical guide for biologists. Biol Rev 82: 591-605. https://doi.org/10.1111/j.1469-185X.2007.00027.x

Paulsen TR, Colville L, Kranner I, Daws MI, Högstedt G, Vandvik V, Thompson K (2013) Physical dormancy in seeds: a game of hide and seek? New Phytol 198:496-503. https://doi.org/10.1111/nph. 12191

Price CJ, Banks PB (2016) Increased olfactory search costs change foraging behaviour in an alien mustelid: a precursor to prey switching? Oecologia 182:119-128. https://doi.org/10.1007/s00442-016-3660$\mathrm{Z}$
Qiu Q, Scott A, Scheerer H, Sapkota N, Lee DK, Ma L, Yu CR (2014) Automated analyses of innate olfactory behaviors in rodents. PLoS One 9:e93468. https://doi.org/10.1371/journal.pone.0093468

R Core Team (2017) R: A language and environment for statistical computing. R Foundation for Statistical Computing, Vienna, Austria

Radwan J, Tkacz A, Kloch A (2008) MHC and preferences for male odour in the bank vole. Ethology 114:827-833. https://doi.org/10. $1111 /$ j.1439-0310.2008.01528.x

Ruxton GD (2009) Non-visual crypsis: a review of the empirical evidence for camouflage to senses other than vision. Philos Trans R Soc B Biol Sci 364:549-557. https://doi.org/10.1098/rstb.2008.0228

Sadowska ET, Baliga-Klimczyk K, Chrzaścik KM, Koteja P (2008) Laboratory model of adaptive radiation: a selection experiment in the bank vole. Physiol Biochem Zool 81:627-640. https://doi.org/ $10.1086 / 590164$

Singer AG, Beauchamp GK, Yamazaki K (1997) Volatile signals of the major histocompatibility complex in male mouse urine. Proc Natl Acad Sci 94:2210-2214

Singleton G (2003) Impacts of rodents on rice production in Asia. IRRI Discuss Pap Ser 45:1-30

Slotnick B, Schellinck H (2002) Behavioral methods in olfactory research with rodents. In: Simon SA, Miguel ALN (eds) Methods in chemosensory research. CRC Press, Boca Raton, pp 21-64

Steele MA, Manierre S, Genna T et al (2006) The innate basis of foodhoarding decisions in grey squirrels: evidence for behavioural adaptations to the oaks. Anim Behav 71:155-160. https://doi.org/10. 1016/j.anbehav.2005.05.005

Takeda H, Tsuji M, Matsumiya T (1998) Changes in head-dipping behavior in the hole-board test reflect the anxiogenic and/or anxiolytic state in mice. Eur J Pharmacol 350:21-29. https://doi.org/10.1016/ S0014-2999(98)00223-4

Taraborelli P, Borruel N, Mangeaud A (2009) Ability of murid rodents to find buried seeds in the Monte desert. Ethology 115:201-209. https://doi.org/10.1111/j.1439-0310.2008.01605.x

Torchiano M (2017) Efficient effect size computation. Retrieved from https://cran.r-project.org/web/packages/effsize/effsize.pdf. Accessed 13 April 2018

Vander Wall SB (2001) The evolutionary ecology of nut dispersal. Bot Rev 67:74-117. https://doi.org/10.1007/BF02857850

Vander Wall SB, Beck MJ, Briggs JS, Roth JK, Thayer TC, Hollander JL, Armstrong JM (2003) Interspecific variation in the olfactory abilities of granivorous rodents. J Mammal 84:487-496

Villalba JJ, Provenza FD (2000) Roles of flavor and reward intensities in acquisition and generalization of food preferences: do strong plant signals always deter herbivory? J Chem Ecol 26:1911-1922

Wernecke KEA, Fendt M (2015) The olfactory hole-board test in rats: a new paradigm to study aversion and preferences to odors. Front Behav Neurosci 9:223. https://doi.org/10.3389/fnbeh.2015.00223

Xiao Z, Zhang Z (2012) Behavioural responses to acorn germination by tree squirrels in an old forest where white oaks have long been extirpated. Anim Behav 83:945-951. https://doi.org/10.1016/j. anbehav.2012.01.013

Publisher's note Springer Nature remains neutral with regard to jurisdictional claims in published maps and institutional affiliations. 